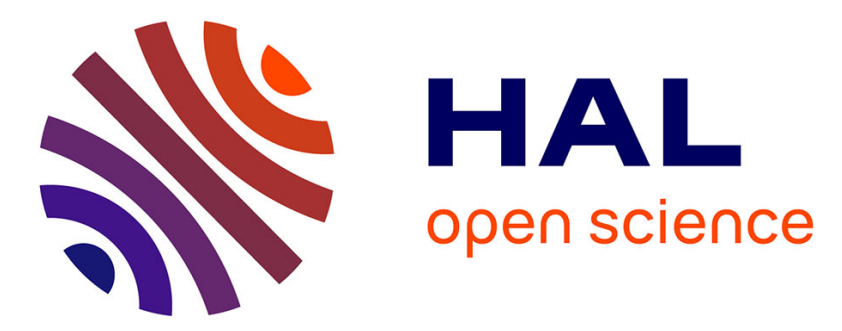

\title{
Epileptogenic networks in nodular heterotopia: A stereoelectroencephalography study
}

Francesca Pizzo, Nicolas Roehri, Hélène Catenoix, Samuel Medina, Aileen

Mcgonigal, Bernard Giusiano, Romain Carron, Didier Scavarda, Karine

Ostrowsky, Anne Lepine, et al.

\section{To cite this version:}

Francesca Pizzo, Nicolas Roehri, Hélène Catenoix, Samuel Medina, Aileen Mcgonigal, et al.. Epileptogenic networks in nodular heterotopia: A stereoelectroencephalography study. Epilepsia, 2017, 58, pp.2112 - 2123. 10.1111/epi.13919 . hal-03500825

\section{HAL Id: hal-03500825 \\ https://hal.science/hal-03500825}

Submitted on 22 Dec 2021

HAL is a multi-disciplinary open access archive for the deposit and dissemination of scientific research documents, whether they are published or not. The documents may come from teaching and research institutions in France or abroad, or from public or private research centers.
L'archive ouverte pluridisciplinaire HAL, est destinée au dépôt et à la diffusion de documents scientifiques de niveau recherche, publiés ou non, émanant des établissements d'enseignement et de recherche français ou étrangers, des laboratoires publics ou privés. 


\section{Epileptogenic networks in nodular heterotopia: A}

\section{stereoelectroencephalography study}

Pizzo, Francesca ${ }^{1,2}$; Roehri, Nicolas ${ }^{1}$; Catenoix, Hélène ${ }^{3}$; Medina, Samuel ${ }^{1}$; McGonigal, Aileen $^{1,2}$; Giusiano, Bernard ${ }^{1,2}$; Carron, Romain ${ }^{1,4}$; Scavarda, Didier ${ }^{1,4}$; Ostrowsky, Karine ${ }^{3}$;

Lepine, Anne ${ }^{5}$; Boulogne, Sébastien ${ }^{3}$; Scholly, Julia ${ }^{6}$; Hirsch, Edouard ${ }^{6}$; Rheims, Sylvain ${ }^{3}$; Bénar, * Christian-George George ${ }^{1}$; ${ }^{*}$ Bartolomei, Fabrice ${ }^{1,2}$

Epilepsia, **(*):1-12, 2017 doi: 10.1111/epi.13919

1 Aix Marseille Univ, INSERM, INS, Inst Neurosci Syst, Marseille 13005, France. 2 APHM, Timone Hospital, Epileptology and cerebral rhythmology, Marseille 13005, France.

3 Department of Functional Neurology and Epileptology, Hospices Civils de Lyon (Lyon University Hospital), Hospital for Neurology and Neurosurgery Pierre Wertheimer, Lyon, France;

4 APHM, Timone Hospital, Functional and Stereotactic Neurosurgery, Marseille 13005, France. 5 Pediatric Neurology Department, Timone Hospital, APHM, Marseille, France 6 Medical and Surgical Epilepsy Unit, Hautepierre Hospital, University of Strasbourg, Strasbourg, France

*These authors contributed equally and are co-last authors 
Nodular heterotopia $(\mathrm{NH})$ is a congenital brain disorder characterized by ectopic position of neurons that are frequently located along the ventricular walls (periventricular nodular heterotopia, $\mathrm{PNH}$ ) or in the deep white matter in form of nodules (subcortical heterotopia)(Barkovich et al., 2012). Epilepsy related to $\mathrm{NH}$ is often drug-resistant and surgery is unlikely to be effective, especially if limited to the resection of the temporal lobe (Dubeau et al., 1995)'(Li et al., 1997). However, good surgical outcome following lesionectomy alone (Kothare et al., 1998)'(Scherer et al., 2005)'(Agari et al., 2012) or associated with resection of the overlying cortex(Aghakhani et al., 2005)'(Tassi et al., 2005) has been reported in a small cohort of patients. Recently, multi-targeting therapies, as thermocoagulation, have been preferred and reported to be effective in this group of patients(Cossu et al., 2014)'(Cossu et al., 2015).

The pathophysiology of these lesions is still not completely understood; genetic factors and toxic exposure during pregnancy(Zhang et al., 1995) both seem to be involved. In the classification of malformation of cerebral cortical development, heterotopia is considered as a malformation due to abnormal neural migration(Barkovich et al., 2012). However, data from animals and humans also demonstrate an abnormal proliferation of cortical progenitors, and as such it seems too restrictive to consider grey matter heterotopia as an exclusively neural migration disorder(Watrin et al., 2015).

Contrary to focal cortical dysplasia (FCD) for which an "intrinsic epileptogenicity" of the lesion has been demonstrated and is widely accepted(Palmini et al., 1995)'(Tassi et al., 2001), the role of the heterotopic lesion in the epileptogenic network involved at seizure onset is still debated(Thompson et al., 2016). A major involvement in epileptogenesis of the cortex surrounding the lesion rather than the lesion itself is suggested by few cases reported after stereoelectroencephalography (SEEG)(Tassi et al., 2005) and by non-invasive studies with EEG- 
functional MRI(Tyvaert et al., 2008). This feature is also supported by animal models of periventricular and band heterotopia, in which heterotopia does not constitute a primary origin for interictal epileptiform activity, its activity being dispensable for generating induced seizures(Petit et al., 2014). In other animal models of heterotopia, however, it has been demonstrated that the lesion can generate epileptiform activity independent of the surrounding neocortex(Tschuluun et al., 2005). Moreover, cortectomy including partial surgical removal of heterotopic nodules seems to correlate with a better surgical outcome (Tassi et al., 2005) than cortectomy alone, implying that there is a normotopic-heterotopic cortex circuitry involved in seizure generation. Furthermore, in animals with experimentally induced $\mathrm{PNH}$, it has been demonstrated that heterotopic neurons can form aberrant connections with the hippocampus, thus giving rise to a complex epileptogenic network(Chevassus-Au-Louis et al., 1998), data confirmed by a human case study(Valton et al., 2008). Tractography studies using diffusion weighted imaging in human subjects confirm aberrant projections suggestive of abnormal white matter organization(Farquharson et al., 2016). However, few human data are available using direct intracerebral EEG recording within distributed networks of $\mathrm{NH}$, in terms of both resting state activity (interictal period) and seizure activity (ictal period).

This study aims to determine biomarkers of epileptogenicity in heterotopic lesion and normotopic cortex by quantifying the seizure onset zone (SOZ) and by studying interictal biomarkers (spikes, HFOs). We reviewed interictal and ictal SEEG recordings in a cohort of epilepsy patients with MRI evidence of $\mathrm{NH}$, recruited from three major tertiary centers in France. We then evaluated different biomarkers of epileptogenicity in heterotopic lesions and normotopic cortex. 


\section{Methods}

\section{Patient selection}

Patients with drug-resistant epilepsy and MRI evidence of heterotopic lesions, who underwent a SEEG study in three French tertiary centers (Marseille, Lyon and Strasbourg) from January 2001 to October 2016, were selected. At the time of the SEEG recording, all patients had a comprehensive evaluation including detailed clinical history and neurological examination, neuropsychological testing, routine MRI and surface EEG. SEEG exploration was carried out during long-term video-EEG monitoring, as part of patients' normal clinical care. Clinical data, SEEG recordings including interictal activity and recorded spontaneous epileptic seizures were collected and analyzed; patients were classified, according to the heterotopic lesion position, as affected by subcortical NH or PNH. PNH patients were also subclassified into unilateral and bilateral (symmetrical and asymmetrical) types(Battaglia et al., 2006).

\section{SEEG recordings}

Recordings were performed using intracerebral multiple contact electrodes (10-15 contacts, length: $2 \mathrm{~mm}$, diameter: $0.8 \mathrm{~mm}, 1.5 \mathrm{~mm}$ apart) placed intracerebrally according to Talairach's stereotactic method(Talairach et al., 1992), or using a frameless stereotactic surgical robot ROSA $^{\mathrm{TM}}$ (Strasbourg). The anatomical targeting of electrodes was established, independently of this study, in each patient according to information available after the non-invasive study and clinical hypotheses about the localization of the epileptogenic zone(Guenot et al., 2002). A postoperative computerized tomography (CT) scan (Marseille, Strasbourg) and/or MRI (Marseille and Lyon) were used to verify the absence of bleeding and the position of electrodes. Video-EEG recording was prolonged as long as necessary in order to record several of the patient's habitual seizures. Finally, CT-scan/MRI data fusion was performed to accurately check the anatomical 
location of each contact along the electrode trajectory according to previously described procedures(Bartolomei et al., 2004) . For this purpose we used our in-house software GARDEL (Marseille) or the free software OsiriX (Strasbourg). GARDEL (a Graphical User Interface for Automatic Registration and Depth Electrodes Localization) is a tool which co-registers MRI to the CT-scan, automatically segments and precisely localizes contacts of depth electrodes by image processing and labels them according to the parcellation of a chosen atlas. It also displays the electrodes on 2 dimensional MRI images as well as 3 dimensional mesh of the brain.

Signals were recorded on a Natus system (Marseille, Strasbourg) or a Micromed system (Lyon). They were sampled at 256,512 or $1024 \mathrm{~Hz}$ at with 16 bits resolution. Two hardware filters were present in the acquisition procedure. The first is a high-pass filter (cut-off frequency equal to 0.16 $\mathrm{Hz}$ - Marseille, Strasbourg - and 0.53 - Lyon - at $3 \mathrm{~dB}$ ) used to remove very slow variations that could contaminate the baseline. The second is an anti-aliasing low-pass filter (cut-off frequency equal to $97 \mathrm{~Hz}$ - Marseille, Strasbourg - and $200 \mathrm{~Hz}$ - Lyon - at 256Hz, $170 \mathrm{~Hz}$ at $512 \mathrm{~Hz}$ and 340 $\mathrm{Hz}$ at $1024 \mathrm{~Hz})$.

\section{SEEG contacts classification and montage selection}

SEEG electrode contacts were classified into three groups according to MRI: "heterotopic cortex" if located within or at the visible borders of the heterotopic tissue(Aubert et al., 2009)'(FerrariMarinho et al., 2015); "local neocortex" if located in the cortex of the same brain lobe as the lesion, but not inside the lesion itself; and "distant neocortex" for all cortical contacts located in other cortical regions. Local neocortex and distant neocortex will be defined as "normotopic cortex" in the following. 
In each patient, to analyze data, a SEEG bipolar montage was created and applied to all recorded seizures and sampled interictal sections. The SEEG montage included all the lesional channels, as well as all channels involved at seizure onset and during approximately the first 10 seconds of each typical patient's seizure.

Channels showing artefacts were excluded from analysis. All signal analysis was computed using the Anywave software(Colombet et al., 2015).

\section{Ictal recordings: visual analysis, computation of the Epileptogenicity Index (EI) and}

\section{seizure classification}

Seizure were collected and visually analyzed, with special attention to the seizure onset patterns(Lagarde et al., 2016) and to the structures involved at seizure onset. All seizures were visually reviewed by one reviewer and then discussed with an expert neurophysiologist. Both were not blinded to the electrode position. An agreement between the two reviewers about structures involved in the epileptic network was always found after discussion.

We then computed the EI for all selected seizures by using our in-house plugin, implemented in the Anywave software.

The EI is a method computed on SEEG signal aiming to quantify the epileptogenicity of brain structures. The EI methodology has been described in previous work(Aubert et al., 2009)'(Bartolomei et al., 2008). This methodology has been applied to the study of different epileptic disorders (cavernous angiomas, focal cortical dysplasia, focal epilepsy with epileptic spasms, temporal, frontal and parietal lobe epilepsy). In summary, the EI is intended to quantify two important features of the transition from pre-ictal to ictal activity on the SEEG signals: (1) the signal energy redistribution from lower frequency band (theta, alpha) towards higher 
frequency band (beta, gamma, high gamma and ripple) and (2) the delay of appearance of these high-frequency components in a given structure with respect to the first structure involved in a "rapid discharge" mode of seizure onset ${ }^{31 .}$ The EI is a normalized quantity ranging from 0 (no epileptogenicity) to 1 (maximal epileptogenicity). This quantity may be estimated using a twostage procedure: (1) within a sliding window (5s duration), the signal energy ratio (ER) is computed, between high [beta (12-24 Hz), gamma (24-127 Hz)] and low [theta (4-7.4 Hz) and alpha $(7.4-12 \mathrm{~Hz})]$ frequency bands of the EEG obtained from the signal spectral density $\mathrm{C}(\mathrm{w})$ (squared modulus of Fourier transform) (2) change-points in the ER[n] quantity, which is sensitive to frequency changes in the signal, are detected. An optimal algorithm ("cumulative sum algorithm" or "CUSUM") is used to automatically determine the time instant when ER[n] increases, that is, when theta alpha activity (predominant in background SEEG signals) changes into higher frequency activity (predominant during the rapid discharge)(Bartolomei et al., 2010). The seizure onset was set visually by the reviewer and then the plugin was launched. The involvement of each structure in the development of the seizure is thus detected, channel by channel, by using the CUSUM algorithm.

Structures involved in the seizure onset as detected by visual analysis and by EI computational analysis were then compared to evaluate concordance between the two analyses. Seizures were classified as heterotopic, normotopic or normo-heterotopic according to the EI value. An EI value of 0.3 was set as a threshold to define a channel as epileptogenic(Bartolomei et al., 2008). When the EI was $\geqslant 0.3$ in the heterotopic cortex only, the seizure was considered "heterotopic" ; when EI was $\geqslant 0.3$ in the local or distant cortex, but not in the heterotopic cortex, this was considered "normotopic" ; when EI was $\geqslant 0.3$ in both heterotopic and local or distant cortex, the seizure was defined "normo-heterotopic". 


\section{Interictal recordings: visual analysis and automatic detection of spikes and HFOs}

Interictal activity in the heterotopic contacts was assessed in all patients' recordings: we observed the background activity and we checked whether IEDs (spikes or spike and wave complexes), slow activities, fast activities and fast oscillations were present.

Five minutes of SEEG sleep recordings (N2 and N3 sleep stages) were then selected for all patients for automatic analysis. Sleep recordings were chosen because they present less movement artefacts and have higher ripple rate(Bagshaw et al., 2009). Each selected sleep recording was at least $24 \mathrm{~h}$ after the SEEG implantation and with $24 \mathrm{~h}$ of distance from a clinical seizure. During these 5 minutes and using the same montage selected for EI calculation, we ran the Delphos HFOs detector to look for ripple oscillations $(80-250 \mathrm{~Hz})$ and spikes. The Delphos detector is based on the ZH0 method(Roehri et al., 2016). The ZH0 method aims at flattening the frequency spectrum to enhance the fast oscillations while preserving an optimal signal to noise ratio at each frequency. This method is based on a continuous analytic wavelet transform and estimation of the noise level at each frequency(Roehri et al., 2016). Most of the HFOs automatically detected were then visually checked for morphological inspection and validation, moreover the Delphos detector was recently validated by using realistic simulation(Roehri et al., 2017).

Spike detection was applied to all patients, whether detection of high frequency oscillations in the ripple band frequency $(80-250 \mathrm{~Hz})$ was only applied to patients who had a $\geq 1024 \mathrm{~Hz}$ night recording (considered the minimum sampling rate required for their correct identification). We further studied the spike-HFO co-occurrence rate. We considered a ripple co-occurring with a spike if the time delay between the ripple and the spike was below $200 \mathrm{~ms}$. 


\section{Statistical analysis}

Two groups were identified for statistical analysis: heterotopic cortex and local neocortex. We did not include distant neocortex in the statistical analysis as these data were not available for 6/19 patients (in these patients SEEG electrodes were not placed in brain regions defined as distant neocortex). Each group was composed by heterotopic or local neocortex channels with the maximal value of each biomarker (EI, HFO rate, spike rate).

The Kolmogorov-Smirnov test was applied to check if these variables (EI values, HFO, spikeHFO co-occurrence and spike rates) had a normal distribution, and since normality was not confirmed for these variables, we used non parametric tests.

We compared the maximal EI value for the 2 groups among seizures $(n=66)$ and among patients ( $\mathrm{n}=19$ - by taking the median EI value for heterotopic and local neocortex group among all seizures recorded from the same patient-).

We then compared the value of maximal HFO, maximal spike-HFO co-occurrence (applied only to patients with recordings sampled at $1024 \mathrm{~Hz}, \mathrm{n}=7$ ) and maximal spike rate (all patients, $\mathrm{n}=19$ ) of the two groups among interictal recordings. A Wilcoxon rank sum test was applied to check statistical significance ( $\mathrm{p}$-value $\leq 0.05$ ). All statistical tests were performed using MATLAB.

\section{Results}

\section{Patients characteristics}

Nineteen patients (12 female, age $32 \pm 11$, epilepsy onset $16 \pm 7$ years, epilepsy duration $15 \pm 9$ years) were studied. Sixteen patients showed MRI findings of PNH and 3 patients showed MRI findings of subcortical $\mathrm{NH}$; three of the patients with $\mathrm{PNH}$ also showed subcortical nodules 
(Table 1); eight PNH were unilateral, 5 bilateral symmetrical and 3 bilateral asymmetric (Battaglia et al., 2006).

Sixty-six seizures were studied. Seven patients had $\geq 1024 \mathrm{~Hz}$ sleep recording. A total of 1246 contacts were analyzed, of them 259 were "heterotopic cortex", 873 were "local neocortex" and 114 were classified as “distant neocortex" channels (Table 1).

Among the 19 patients, 4 were subsequently operated following SEEG (P4, P7, P10, P16), 4 refused surgery and in two patients surgery was contraindicated (P1 and P8, bitemporal epilepsy) (Table 1). Engel class I after surgery was obtained only for P7 (temporo-occipital disconnection). Ten patients had thermocoagulation: one patient reported a good persistent (>18 months) response (P2); 3 patients $(\mathrm{P} 11, \mathrm{P} 12, \mathrm{P} 15)$ showed an initially good response that in 2 proved to be transitory (P15 - no responder -, P12 -partially responder, Engel class III-) and in one (P11) not enough follow up is still available (good responder at 12 months); two patients reported a partial response (P13 and P19- Engel class III) and 4 patients had no response. Among the nonresponders to thermocoagulation, one patient had subsequently been operated (P16) for a right temporo-occipital cortectomy that was not effective at 3 months follow up 
Table 1: Clinical, MRI and SEEG patients' characteristics

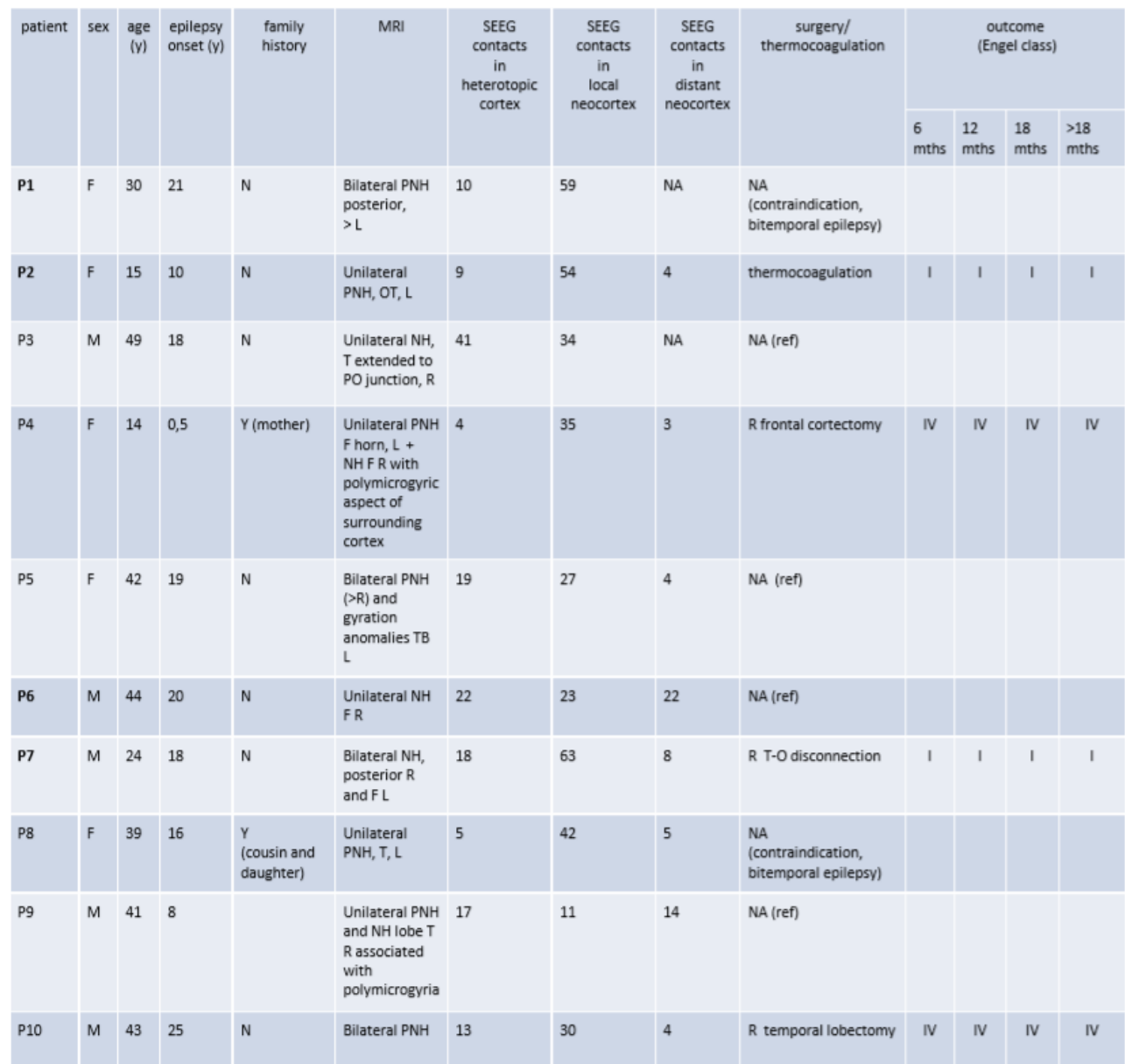

\begin{tabular}{|c|c|c|c|c|c|c|c|c|c|c|c|c|c|}
\hline P11 & $\mathrm{F}$ & 42 & 33 & N & $\begin{array}{l}\text { Unilateral PNH } \\
\text { and NH TPO R }\end{array}$ & 27 & 63 & 8 & thermocoagulation & 1 & 1 & & \\
\hline P12 & M & 24 & 14 & $\begin{array}{l}Y \\
\text { (cousin) }\end{array}$ & $\begin{array}{l}\text { Unilateral PNH } \\
\text { FL }\end{array}$ & 12 & 61 & NA & thermocoagulation & 1 & III & & \\
\hline P13 & $\mathrm{F}$ & 28 & 16 & $\mathrm{~N}$ & $\begin{array}{l}\text { Bilateral PNH } \\
\text { TPO }\end{array}$ & 12 & 34 & NA & thermocoagulation & III & III & III & III \\
\hline P14 & $\mathrm{F}$ & 29 & 20 & $\mathrm{~N}$ & $\begin{array}{l}\text { Unilateral PNH } \\
\text { TOL }\end{array}$ & 3 & 38 & 10 & thermocoagulation & IV & & & \\
\hline P15 & M & 31 & 11 & N & $\begin{array}{l}\text { Bilateral PNH } \\
\text { TPO }\end{array}$ & 17 & 30 & NA & thermocoagulation & 1 & 1 & I & IV \\
\hline P16 & $\mathrm{F}$ & 16 & 12 & $\mathrm{~N}$ & Bilateral PNH & 4 & 73 & 14 & $\begin{array}{l}\text { thermocoagulation } \\
\text { followed by } T-0 \\
\text { cortectomy }\end{array}$ & IV & & & \\
\hline P17 & $\mathrm{F}$ & 27 & 24 & $\mathrm{~N}$ & $\begin{array}{l}\text { Bilateral PNH } \\
\text { TPO, }>\text { R }\end{array}$ & 10 & 53 & 8 & thermocoagulation & IV & & & \\
\hline P18 & $\mathrm{F}$ & 52 & 21 & N & $\begin{array}{l}\text { Bilateral PNH } \\
\text { TPO }\end{array}$ & 10 & 64 & NA & thermocoagulation & IV & & & \\
\hline P19 & $\mathrm{F}$ & 21 & 16 & $\begin{array}{l}\text { Y } \\
\text { (grandfather) }\end{array}$ & $\begin{array}{l}\text { Unilateral } \\
\text { PNH, TPO L }\end{array}$ & 6 & 79 & 10 & thermocoagulation & III & & & \\
\hline
\end{tabular}

Patients in bold have a night recorded at $\geq 1024 \mathrm{~Hz}$. PNH: periventricular nodular heterotopia, $\mathrm{NH}$ : nodular heterotopia, T: temporal, B: basal, O: occipital, P: parietal, F: frontal, L: left, R: right, $\mathrm{mths:}$ months; NA not applicable; Ref patient refused surgery 


\section{Ictal SEEG: Epileptogenicity Index and seizure characteristics in normotopic and}

\section{heterotopic cortex}

The seizure onset patterns(Lagarde et al., 2016) disclosed some specificity and heterogeneity across patients and among the different seizures of the same patient. We observed that the same seizure, involving both heterotopic and normotopic cortex, could share different patterns into the two structures. A fast discharge could be present on the heterotopic cortex, followed or not by a rhythmic activity, and, at the same time, a rhythmic theta or spiking activity is recorded in the normotopic cortex. In these cases we considered both structures involved in the seizure and we selected the fast discharge pattern as the main pattern.

We noticed that when the heterotopic cortex is implicated at seizure onset in visual analysis (45/66 seizures and 17/19 patients), we always observed in at least one contact in the lesion, a pattern of typical low voltage fast discharge (LVFA) (44) or a particular very fast rhythmic spikes discharge (1 seizure in P5) associated or not with a preceding slow wave or pre-ictal spiking. Table $\mathrm{S} 1$ indicates the main visual analysis findings in the 19 patients.

The highest value of EI is reported, color coded, for each patient's seizure and for each group of channels (heterotopic cortex, local neocortex, distant neocortex) in Fig 1A.

The computational and visual analysis are in general good agreement (50/66 seizures) concerning the structures (heterotopia, local neocortex and distant neocortex) involved in the epileptic network. However, in some cases (16/66 seizures in 9 patients) the visual analysis is in partial disagreement with the computational analysis. Among these cases, in the majority (13/16) the visual analysis tends to evaluate a larger epileptic network than the one evidenced by computational analysis. In the other few cases (3/16) the EI pointed as epileptogenic some brain regions not clearly involved by visual analysis. 
Analyzing the EI values among seizures the epileptogenicity of the local neocortex group (median $1,1^{\text {st }}$ quartile - Q1 - 0.60 and $3^{\text {rd }}$ quartile - Q3 - 1.00) was significantly higher $(\mathrm{p} \leq 0.001)$ compared to the heterotopic group (median 0.43, Q1 0.09 and Q3 1) (Fig 1B). Among patients no significant difference $(\mathrm{p}=0.07)$ in epileptogenicity was found by comparing the two groups (heterotopic group: median 0.72, Q1 0.18 and Q3 0.99; local neocortex group: median 1, Q1 0.63 and Q3 1). However the boxplot of the medians for patients (of the EI max of seizures) (Fig 1C) showed in our cohort of patients, that the median EI value on the local neocortex was higher compared to the heterotopic cortex.

We estimate that one of the causes of non-significant $p$ value at a patient level analysis could be linked to the too large variance of the EI values for the heterotopic cortex (Fig 1C). This variance could be explained considering the small sample size and the lower number of contacts in this group compared to local neocortex group. 
A

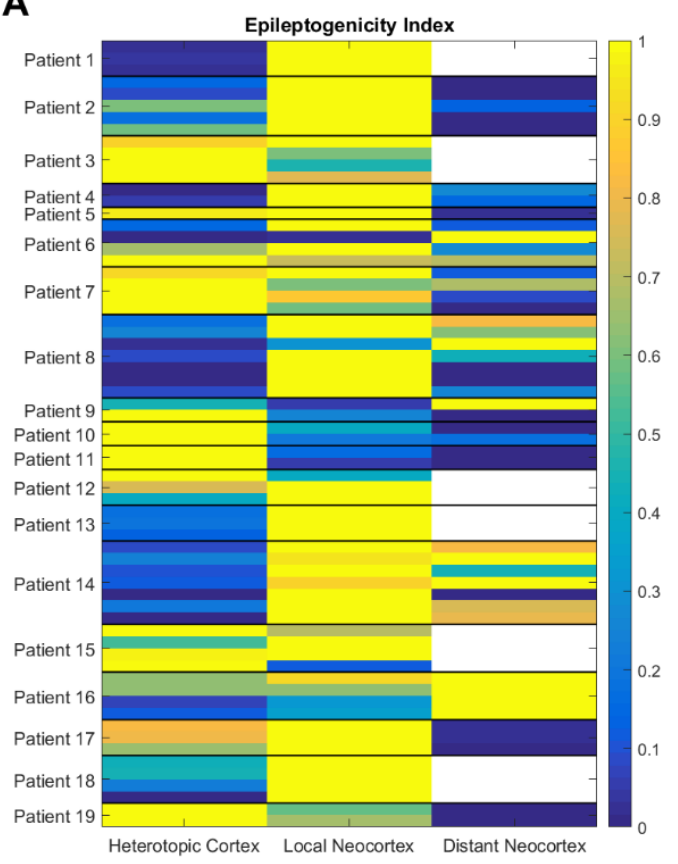

B

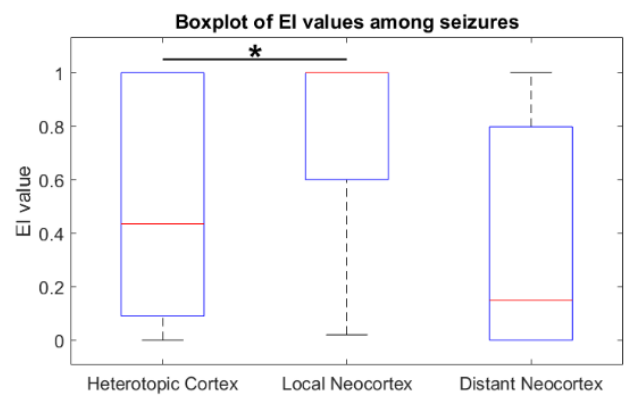

C

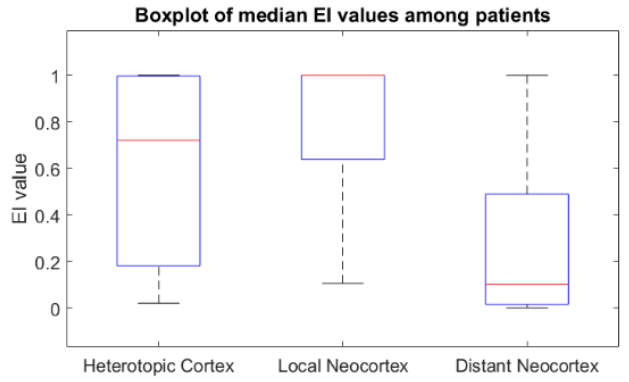

Fig 1: Epileptogenicity index trough seizures and patients A. EI max values (refer to color bar) for groups of contacts (columns- heterotopic cortex, local neocortex and distant neocortex) for each patient's seizure (lines). The yellow bands indicate the highest EI values. Note that the most epileptogenic structure is often within local neocortex $(\mathrm{p}<0.001)$, but marked heterogeneity in the epileptogenic profile is observed. B. Boxplot of the EI max values among seizure in each group of contacts: a significant difference $(*)$ was found comparing local neocortex and heterotopic cortex C. Boxplot of the median EI values among patients: no significant difference was found comparing local neocortex and heterotopic cortex. To note local neocortex showed a higher median compared to heterotopic cortex.

One example of each seizure type according to EI is reported in Fig 2 (heterotopic seizure), Fig 3 (normotopic seizure) and Fig 4 (normo-heterotopic seizure). According to EI analysis, a 
preponderance of normotopic $(32 / 65,48.5 \%)$ and normo-heterotopic $(30 / 65,45.5 \%)$ seizures were detected, while heterotopic seizures were the least represented $(4 / 65,6 \%)$. In the majority of patients $(13 / 19)$ both cortices $(\mathrm{EI}>0.3)$ participate in the seizure network, experiencing at least one normo-heterotopic seizure. Five patients presented exclusively normotopic seizures. Heterotopic seizures were found in P9, P11 (unilateral PNH with associated subcortical nodules) and P10 (bilateral symmetrical heterotopia). Only one of these patients (P11) had heterotopic seizures as the unique seizure type. For a given patient (patients 6, 7, 12 and 15, Fig 1A, all with normo-heterotopic seizures) the leader structure (highest EI value) at seizure onset could change, being once the heterotopic cortex and once the local or distant cortex. Due to the low number of patients in each subcategory related to MRI findings, we were not able to compute statistical analysis comparing this feature with the seizure type as classified by EI 
A

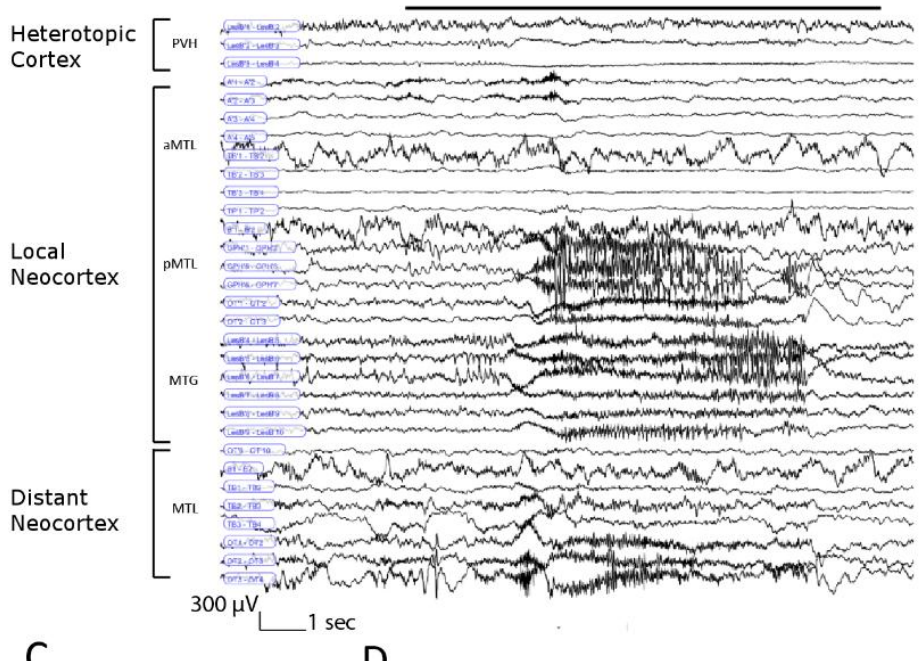

C
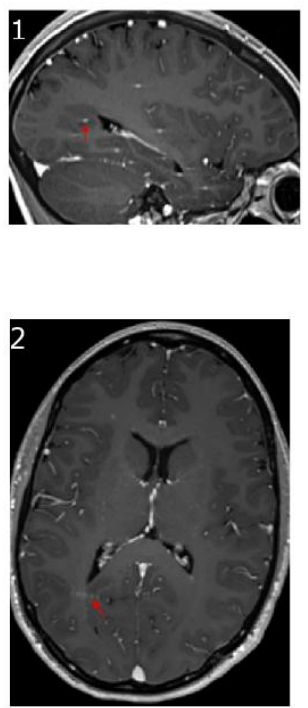

B

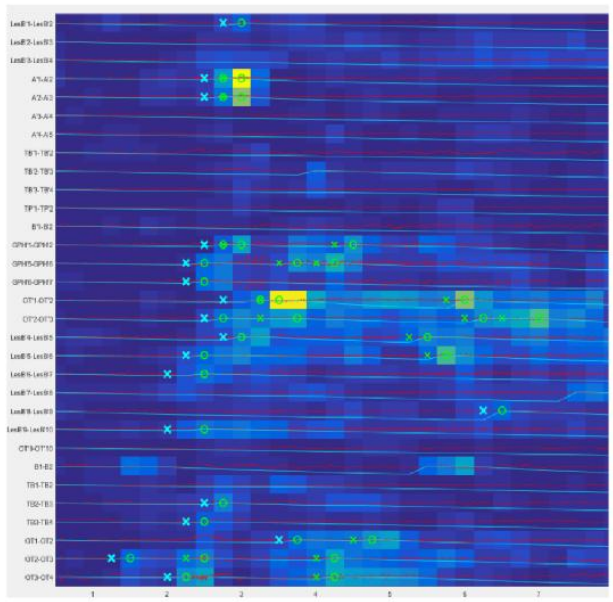

$\mathrm{E}$

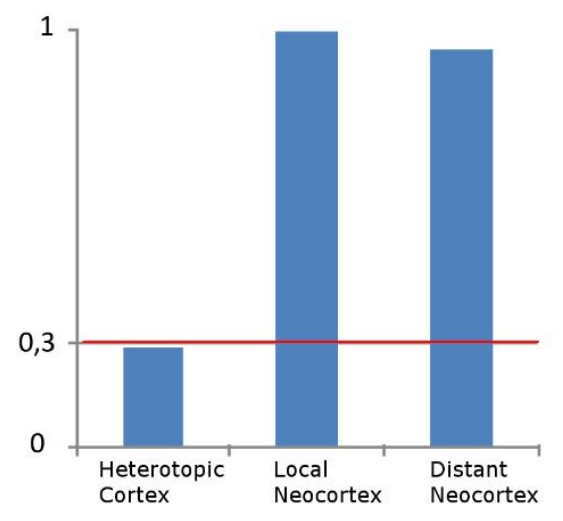

Fig 2. Non-heterotopic seizure in P14 A. SEEG recording from the heterotopic cortex, local neocortex and distant neocortex. The heterotopic cortex is explored in the posterior periventricular region $(\mathrm{PVH})$. Local neocortex is showed in the anterior mesial temporal lobe (aMT), posterior mesial temporal region (pMTL) and middle temporal gyrus (MTG). Distant neocortex is showed in the contralateral mesio-temporal regions (MTL). The black line on the top identifies the SEEG segment analyzed in the EI map B. The EI map showed the increase in energy ratio (in blue to yellow scale) and the time of detection (circle - alarm time- and cross - 
detection time(Bartolomei et al., 2008)) in each SEEG channel selected. The highest epileptogenicity is detected in the local neocortex. C MRI (T1 sequence) - CT data fusion 1,2 Electrode LesB' placed in the heterotopic cortex. The red arrow indicates contact \# 2 D 3D representation of the SEEG exploration; the balloons indicate the EI detections. Balloon color (from yellow to red) and dimension correspond to the EI value. To note the widespread network involved in the epileptogenicity in the local and distant neocortices, but not in the heterotopia (mesial contacts of electrode Les'B). E EI maximal values obtained in each group of contacts in this seizure. The red line marks the 0.3 value considered as a threshold to define a region as epileptogenic. Both local and distant neocortex showed a high degree of epileptogenicity, while heterotopic cortex is not involved, identifying this seizure as a normotopic seizure. 
A

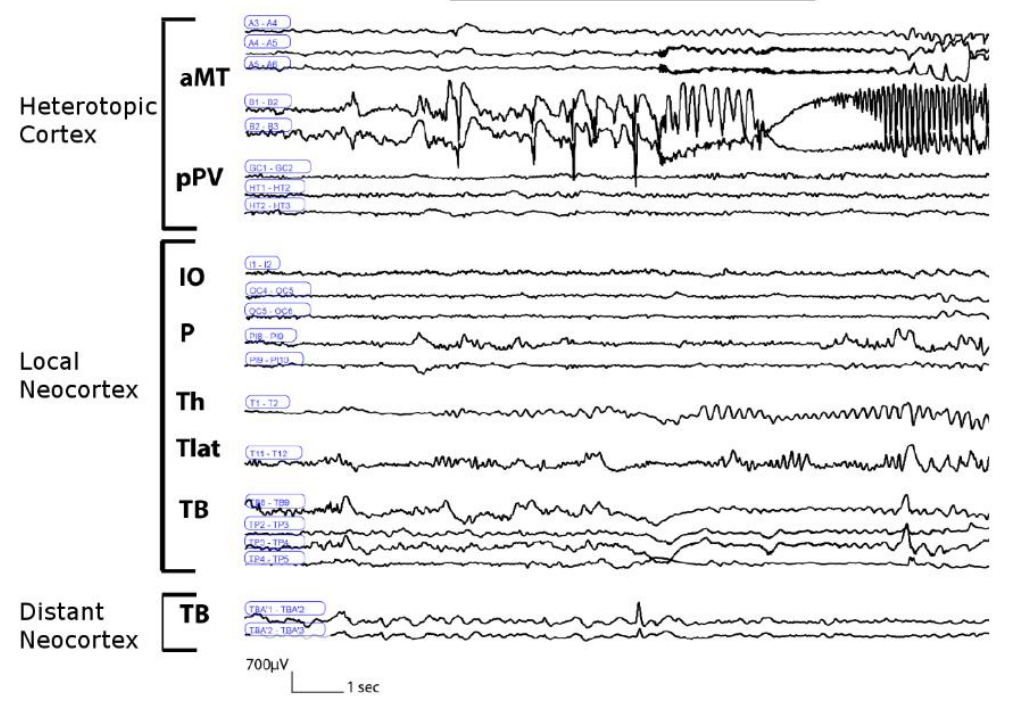

C
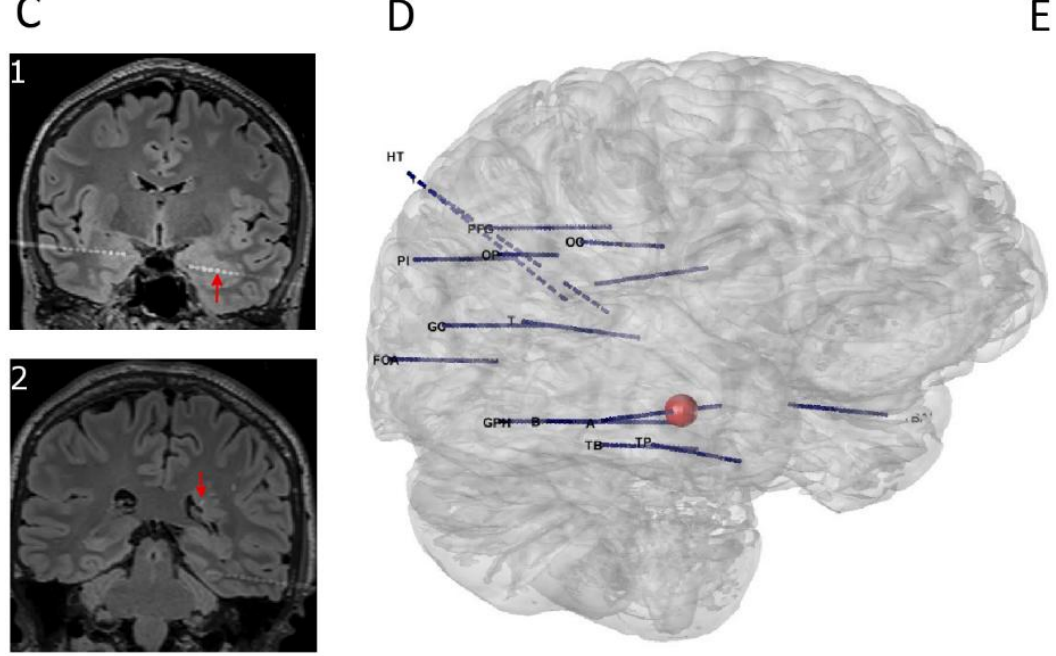

B

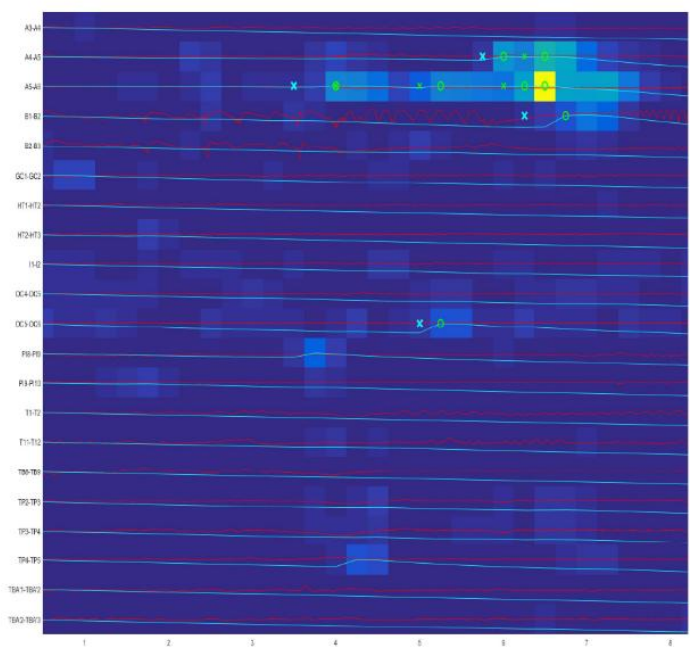

$\mathrm{E}$

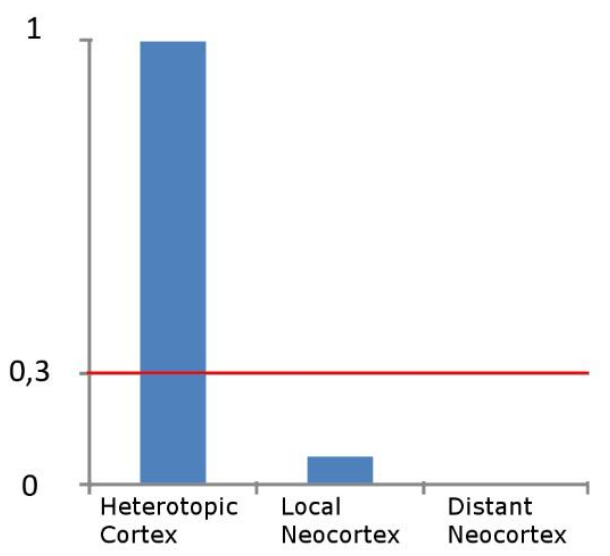

Fig 3. Heterotopic seizure in P11 A. SEEG recording from the heterotopic cortex, local neocortex and distant neocortex. The heterotopic cortex is explored in the anterior mesial temporal lobe (aMT) and in the posterior periventricular region (pPV). Local neocortex is shown in the insuloopercular region (IO), parietal lobe $(\mathrm{P})$, thalamus $(\mathrm{Th})$ lateral temporal lobe (Tlat) and temporobasal region (TB). Distant neocortex is shown in the contralateral TB region. The black line on the top identifies the SEEG segment analyzed in the EI map B. The EI map shows increase in energy ratio (in blue to yellow scale) and time of detection (circle - alarm time- and cross detection time(Bartolomei et al., 2008)) in each SEEG channel; local neocortex appears to be the 
most epileptogenic. C. MRI (FLAIR sequence) - CT data fusion 1 Electrode A, in blue, placed in the heterotopic cortex in the temporal lobe. The red arrow indicates contact \#5 2 Electrode HT, in blue, placed in the periventricular heterotopic cortex. The white arrow indicates contact \#1 D. 3D representation of the SEEG exploration; the balloons indicate the EI detections on SEEG contacts. Balloon color (from yellow to red) and dimension correspond to the EI value. To note the focal epileptogenicity in the heterotopic channel in the MTL (internal-median contacts of electrode A) E. EI maximal values obtained in each group of contacts in this seizure. The red line marks the 0.3 value considered as a threshold to define a region as epileptogenic. Only heterotopic contacts are higher than 0.3 , identifying this seizure as a heterotopic seizure. 
A

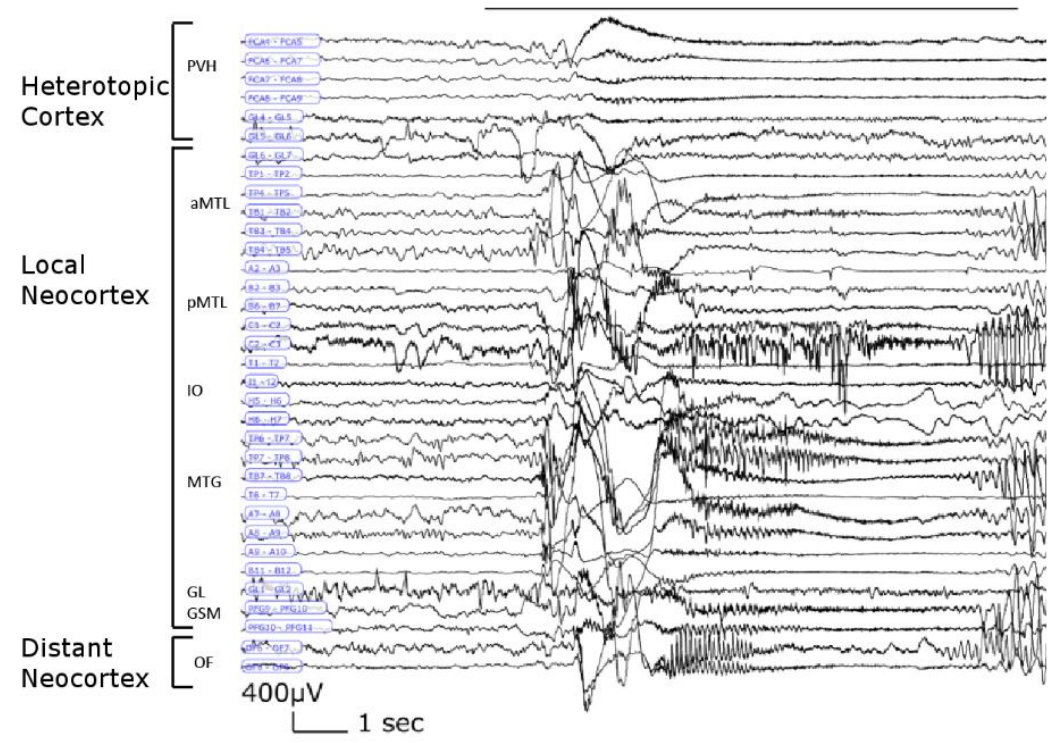

C
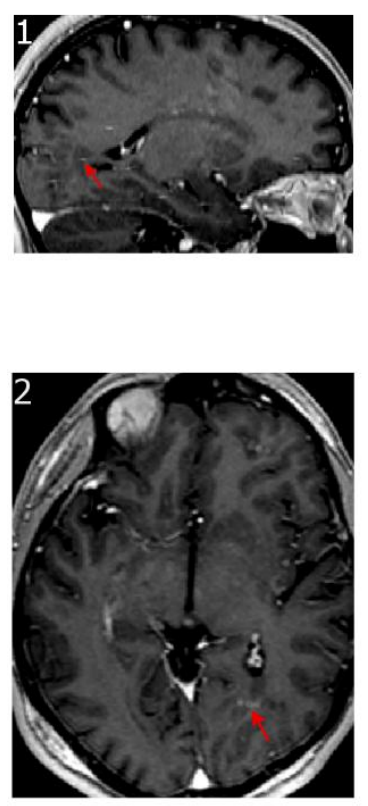

B

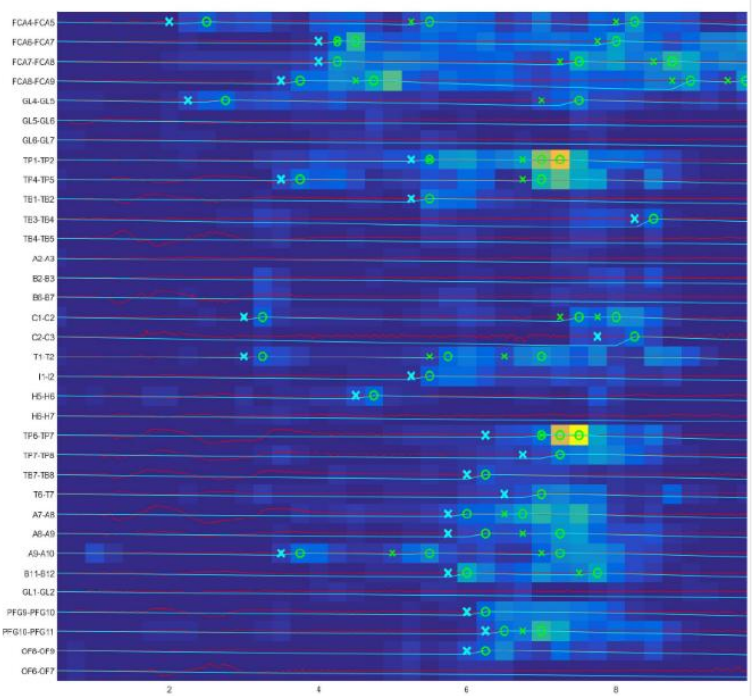

$\mathrm{E}$

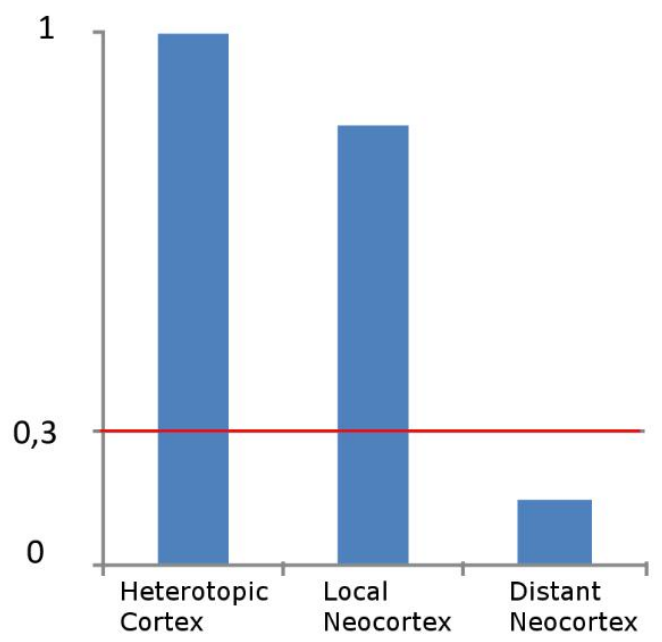

Fig 4. Normo-heterotopic seizure in P7 A. SEEG recording from the heterotopic cortex, local neocortex and distant neocortex. The heterotopic cortex is explored in the posterior periventricular region $(\mathrm{PVH})$. Local neocortex is showed in the anterior mesial temporal lobe (aMT), posterior mesial temporal region (pMTL), insulo-opercular region (IO), middle temporal gyrus (MTG), gyrus lingualis (GL) and gyrus supra-marginalis (GSM). Distant neocortex is 
showed in the fronto-opercular region (OF). The black line on the top identifies the SEEG segment analyzed in the EI map B. The EI map showed increase in energy ratio (in blue to yellow scale) and time of detection (circle - alarm time- and cross -detection time(Bartolomei et al., 2008)) in each SEEG channel selected. The epileptogenicity is high in both local neocortex and heterotopic cortex. C. MRI (3D T1) - CT data fusion 1, 2 Electrode FCA placed inside the heterotopic cortex. The red arrow indicates contact \#4 D. 3D representation of the SEEG exploration; the balloons indicate the EI detections. Balloon color (from yellow to red) and dimension correspond to the EI value. To note the diffuse epileptogenicity involving both local neocortex (electrodes TP, A and T) and heterotopic cortex (mesial contacts of GL and median contacts of FCA). E. EI maximal values obtained in each group of contacts in this seizure. The red line marks the 0.3 value considered as a threshold to define a region as epileptogenic. Both local neocortex and heterotopic cortex showed a high degree of epileptogenicity, identifying this seizure as a normo-heterotopic seizure.

\section{Interictal recordings: heterotopic cortex activity and normo-heterotopic cortex}

\section{comparison}

Interictal activity in heterotopic cortex was of generally low amplitude and characterized by epileptic anomalies in the form of spike and spike and wave complexes (all patients). Fast activity was often found (14 pts), possibly visible superimposed on the slow wave following the spike. Slow "lesional" activity was observed in 8 patients. Ripples were found in the heterotopic channels in all 7 patients with a $\geq 1024 \mathrm{~Hz}$ night recording, although in 3 patients (P6, P11, P14) the rate was low (rate $\leq 1 / \mathrm{min})$ (Table $\mathrm{S} 1)$. 
No significant difference was found $(p>0.05)$ between heterotopic cortex and local neocortex comparing the interictal HFO normalized rate (7 patients), the interictal spike normalized rate (19 patients) and the interictal spike-ripple co-occurrence normalized rate (7 patients) (Fig. 5).

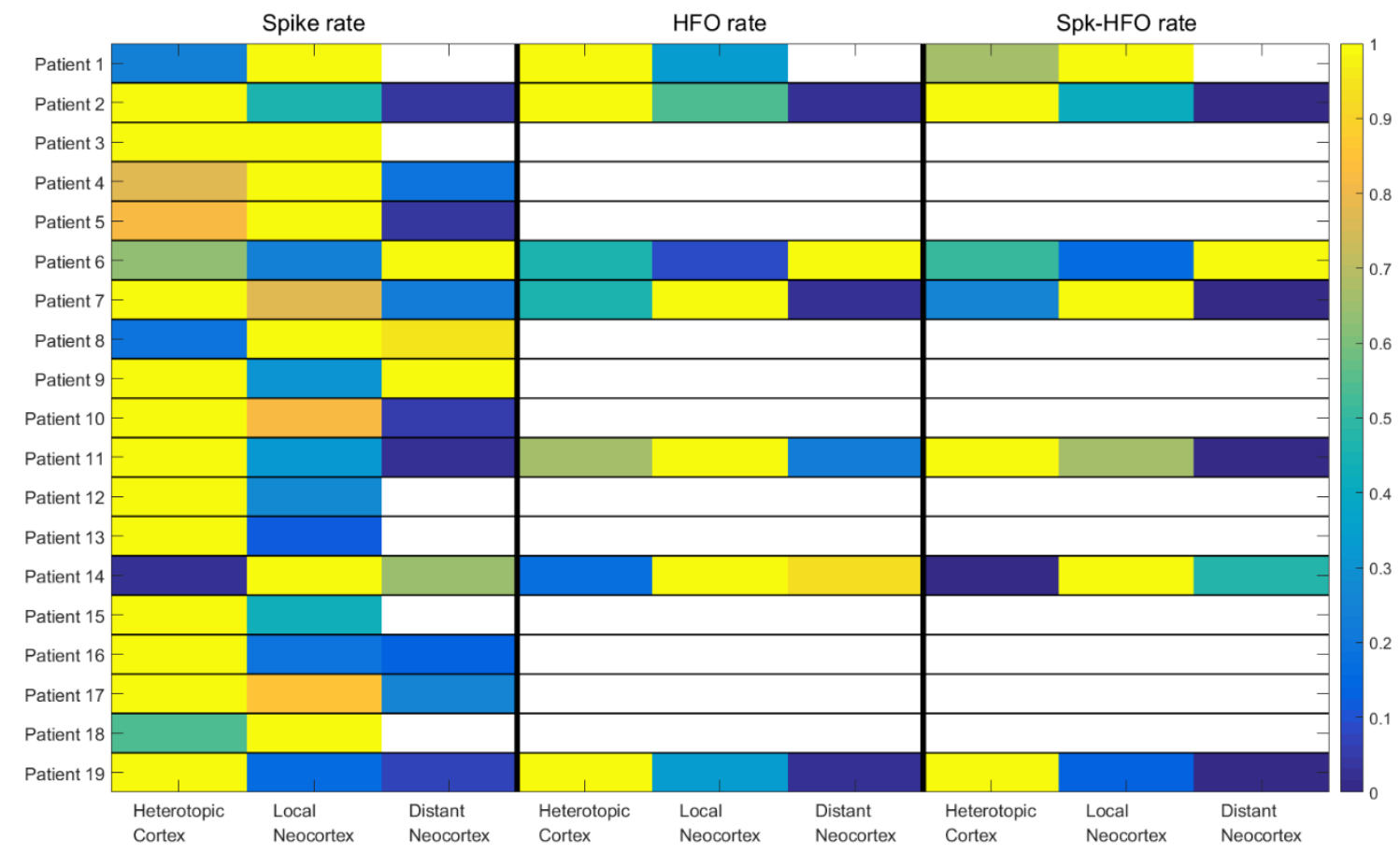

Fig 5: Spike, HFO, and spike-HFO co-occurrence normalized interictal rates (max value) for groups of contacts in each patient. No significant difference comparing local neocortex and heterotopic cortex was found for interictal markers.

\section{Discussion}

By quantifying different neurophysiological biomarkers of epileptogenicity across a series of patients with $\mathrm{NH}(\mathrm{n}=19)$ explored with intracerebral EEG, we found that both heterotopic and 
normotopic cortices are involved in the epileptogenic network and that their role could vary considerably from one patient to another.

This study provides a quantification of epileptogenic networks in patients with epilepsy related to heterotopia, based on direct intracerebral signals including both interictal and ictal EEG data.

\section{Quantification of epileptogenicity: ictal recordings}

We demonstrated that heterotopic and normotopic cortices are involved in a complex seizure network in the majority of patients, with the normotopic cortex showing a higher degree of epileptogenicity as quantified by EI analysis of all seizures recorded. These observations are in accord with the previous literature in which is often reported a simultaneous involvement of the lesion and the normotopic cortex(Aghakhani et al., 2005)'(Tassi et al., 2005)'(Valton et al., 2008)'(Kobayashi et al., 2006) as well as a major role of the normotopic cortex in the epileptogenesis both in humans studies(Tassi et al., 2005)'(Tyvaert et al., 2008) and in animal models(Tschuluun et al., 2005).

Seizures differed greatly among patients and indeed within the same patient, concerning the involvement of heterotopic and normotopic cortex in the development of the ictal discharge. Most of the seizures according to EI were however either normotopic (involving local or distant neocortical regions) or normo-heterotopic (involving both neocortex and heterotopic cortex), with a scant representation of pure heterotopic seizures (6\%).

Taken as a whole, these results suggest a more complex relationship between heterotopic lesions and the other cortical regions when compared with FCD, another type of malformation of cortical development. In our previous study on $\mathrm{FCD}$ (Aubert et al., 2009), EI values were clearly higher in the lesion compared to other structures, demonstrating an "intrinsic epileptogenicity" of the 
FCD. In NH the relation between normotopic cortex and lesion during seizures appear more complicated and strongly heterogeneous. This heterogeneity suggests that the epileptogenic effect of NH may vary greatly between cases, and that in the majority of cases the nodule itself may not in fact directly play a "orchestrating" or "synchronizing" role(Thompson et al., 2016).

\section{Interictal markers of epileptogenicity: visual analysis and quantification}

We observed interictal activity inside the nodule characterized by low voltage background with rare to abundant IEDs (Table S1); this kind of activity has previously been reported(Tassi et al., 2005). Ripples have been detected and observed in few patients with $\mathrm{NH}$ (Ferrari-Marinho et al., 2015)' (Jacobs et al., 2009), in the present study we confirmed this data on a larger population. We observed that fast oscillations (gamma and ripple) in heterotopia could be found superimposed on the slow wave following the spike, and that brief low voltage gamma-ripple band discharges are possibly recorded in the nodules. Statistical analysis did not show significant differences between heterotopic cortex and local neocortex comparing spike, HFO and spikeHFO co-occurrence rates, demonstrating a distributed epileptogenicity also during interictal recordings.

Few previous studies have explored interictal spike(Jacobs et al., 2009) and HFOs rates (FerrariMarinho et al., 2015)' (Jacobs et al., 2009) in NH using SEEG recording. In the three patients with NH studied by Jacobs et al.(Jacobs et al., 2009), spikes and HFOs have been reported inside the SOZ, which was often in the normotopic cortex, and rarely inside the heterotopic lesion that was usually "silent". The correlation of HFOs and SOZ in NH was evident for spikes and fast ripples but not for ripples that showed a more widespread distribution(Jacobs et al., 2009). 
The relation between HFO and SOZ in NH needs to be better elucidated: Ferrari et al.(FerrariMarinho et al., 2015) showed that HFOs are related to the lesion, and that FCD, mesial temporal sclerosis and NH all showed a higher HFO rate compared to other lesion types. Our study confirms Ferrari's findings, since ripple oscillations were found within the heterotopic lesion in all patients.

In summary, our analysis in the interictal period did not show differences in epileptogenicity between the heterotopic cortex and local neocortex. In particular, regarding the ripple band frequency analysis, we confirmed the presence of HFOs in both heterotopic and normotopic cortex; however, whether this activity is strictly linked to epileptogenicity remains to be clarified. This emphasizes the need for other biomarkers of epileptogenicity that could be applied during interictal recordings in patients with NH. A recent study using transcranial magnetic resonance in association with scalp EEG and prior functional MRI (fMRI), demonstrated changes consistent with cortical hyperexcitability within grey matter structures showing aberrant connectivity with regards to the heterotopic lesion(Shafi et al., 2015).

\section{Surgical procedure and outcome}

Different surgical techniques other than resective surgery have been applied to patients with epilepsy related to heterotopia. Stereotactic MRI guided laser interstitial thermal therapy is one such non-resective method $^{15}$. Another method is thermocoagulation(Catenoix et al., 2008)' (Catenoix et al., 2015), which allows targeting of multiple brain areas, possibly modifies the aberrant connections of the epileptogenic networks, and has been shown to be particularly effective in NH patients(Cossu et al., 2014)'(Cossu et al., 2015). In our series however, most of the patients had a transitory, mild or no effect following thermocoagulation, except for one patient who was seizure free at $>18$ months. A good long-term outcome was indeed obtained for 
patient 7 (bilateral $\mathrm{NH}$ ) with normo-heterotopic seizures after right temporo-occipital disconnection surgery.

From animal models(Tschuluun et al., 2005)'(Chevassus-Au-Louis et al., 1998) it is known that PNH structures produce aberrant connectivity between normally unconnected brain regions, thus creating a novel pathway by which epileptiform activity can more easily spread to relatively normal brain regions. In humans, structural connectivity between nodules and cortical regions was evidenced by a tractography study(Christodoulou et al., 2012) and resting state functional connectivity confirmed by a recent TMS/EEG/fMRI study (Shafi et al., 2015). In animal models(Tschuluun et al., 2005), as in humans, in the same subject variable involvement of different brain areas at seizure onset can be observed, shifting the leader role from normotopic to heterotopic cortex. In this extended and heterogeneous network pathology, when surgery is contraindicated, multiple target treatments such as thermocoagulation or disconnection so far appear to be effective(Cossu et al., 2014)'(Cossu et al., 2015)' (Catenoix et al., 2008).

\section{Limitations of the study}

The greatest limitations of the study are the relative small number of patients and the different approaches to surgery therefore it is not possible to make any definite statement about surgical outcome. Other limitations relate to the heterogeneity of the population, which includes subjects with unilateral and bilateral PNH and subcortical nodules. However, since the opportunity to study NH patients implanted for SEEG recordings is rare (19 patients studied in 3 tertiary French centers in 15 years), it is thus difficult to obtain more detailed analysis for subtypes of patients. 


\section{Concluding remarks}

This is the first study to our knowledge in NH patients in which electrophysiological activities from heterotopic and normotopic cortex are quantified and compared during ictal and interictal recordings in a relatively large population of patients explored invasively by SEEG. Our study confirms that epilepsy related to $\mathrm{NH}$ is a disease of distributed networks in which both heterotopic and neocortical regions contribute to ictogenesis(Valton et al., 2008). The epileptic networks related to NH result from both structural(Tschuluun et al., 2005)'(Chevassus-Au-Louis et al., 1998) and functional(Christodoulou et al., 2012) altered connectivity. Heterogeneity in the development of the epileptic networks related to $\mathrm{NH}$ is one of the remarkable characteristics of this population. 
Supplementary materials: Tab 1

\begin{tabular}{|c|c|c|c|c|c|c|c|c|c|}
\hline \multirow[t]{2}{*}{ patient } & \multirow{2}{*}{$\begin{array}{l}\text { number of } \\
\text { seizures } \\
\text { analyzed }\end{array}$} & \multicolumn{3}{|c|}{ structures involved at seizure onset $\%$ (number) } & \multirow{2}{*}{$\begin{array}{l}\text { interictal recordings } \\
\text { from heterotopic cortex }\end{array}$} & \multicolumn{4}{|c|}{ seizure onset patterns $\%$ (number) } \\
\hline & & $\begin{array}{l}\text { heterotopic } \\
\text { cortex }\end{array}$ & $\begin{array}{l}\text { normotopic cortex } \\
\text { (local and/or distant } \\
\text { neocortex) }\end{array}$ & $\begin{array}{c}\text { Heterotopic } \\
\text { and normotopic } \\
\text { cortex }\end{array}$ & & $\begin{array}{c}\text { slow wave } \\
+ \\
\text { low voltage } \\
\text { fast activity }\end{array}$ & $\begin{array}{l}\text { low } \\
\text { voltage } \\
\text { fast } \\
\text { activity }\end{array}$ & $\begin{array}{l}\text { rhythmic } \\
\text { spikes }\end{array}$ & $\begin{array}{c}\text { preictal } \\
\text { spiking } \\
+\end{array}$ \\
\hline P1 & 3 & & $33(1)$ & $66(2)$ & $\begin{array}{c}\text { Spike, Spike-wave, fast } \\
\text { activity, HFO }\end{array}$ & $66(2)$ & $33(1)$ & & \\
\hline P2 & 5 & & & $100(5)$ & $\begin{array}{c}\text { Spike, Spike-wave, fast } \\
\text { activity, HFO }\end{array}$ & $80(4)$ & $20(1)$ & & \\
\hline P3 & 4 & & & $100(4)$ & $\begin{array}{l}\text { Spike, Spike-wave, fast } \\
\text { activity }\end{array}$ & $100(4)$ & & & \\
\hline P4 & 2 & & $100(2)$ & & $\begin{array}{c}\text { Slow activity, Spike, Spike- } \\
\text { wave }\end{array}$ & & & $100(2)$ & \\
\hline P5 & 1 & & & $100(1)$ & $\begin{array}{c}\text { Slow activity, Spike, Spike- } \\
\text { wave, fast activity }\end{array}$ & & & $100(1)$ & \\
\hline P6 & 4 & & $25(1)$ & $75(3)$ & $\begin{array}{l}\text { Slow activity, Spike, Spike- } \\
\text { wave, fast activity, rare HFO }\end{array}$ & $75(3)$ & & & $25(1)$ \\
\hline P7 & 4 & & & $100(4)$ & $\begin{array}{l}\text { Slow activity, Spike, Spike- } \\
\text { wave, fast activity, HFO }\end{array}$ & $75(3)$ & $25(1)$ & & \\
\hline P8 & 7 & & $70(5)$ & $30(2)$ & $\begin{array}{l}\text { Slow activity, Spike, Spike- } \\
\text { wave }\end{array}$ & $58(4)$ & $14(1)$ & $28(2)$ & \\
\hline Pg & 2 & $50(1)$ & $50(1)$ & & $\begin{array}{c}\text { Slow activity, Spike, Spike- } \\
\text { wave, fast activity }\end{array}$ & & $100(2)$ & & \\
\hline P10 & 2 & $50(1)$ & $50(1)$ & & $\begin{array}{c}\text { Spike, Spike-wave, fast } \\
\text { activity }\end{array}$ & $50(1)$ & $50(1)$ & & \\
\hline P11 & 2 & $100(2)$ & & & $\begin{array}{l}\text { Spike, Spike-wave, fast } \\
\text { activity, rare HFO }\end{array}$ & & $100(2)$ & & \\
\hline P12 & 3 & & & $100(3)$ & $\begin{array}{c}\text { Slow activity, Spike, Spike- } \\
\text { wave, fast activity }\end{array}$ & & $66(2)$ & & $33(1)$ \\
\hline P13 & 3 & & $33(1)$ & $66(2)$ & Spike, Spike-wave & & $33(1)$ & $66(2)$ & \\
\hline P14 & 7 & & $100(7)$ & & rare Spike and HFO & $42(3)$ & $58(4)$ & & \\
\hline P15 & 4 & & & $100(4)$ & $\begin{array}{l}\text { Spike, Spike-wave, fast } \\
\text { activity }\end{array}$ & $25(1)$ & & & $75(3)$ \\
\hline P16 & 4 & & $50(2)$ & $50(2)$ & Spike, Spike-wave & $100(4)$ & & & \\
\hline P17 & 3 & & & $100(3)$ & $\begin{array}{c}\text { Spike, Spike-wave, fast } \\
\text { activity }\end{array}$ & $100(3)$ & & & \\
\hline P18 & 4 & & $50(2)$ & $50(2)$ & $\begin{array}{l}\text { Spike, Spike-wave, fast } \\
\text { activity }\end{array}$ & $50(2)$ & & $50(2)$ & \\
\hline P19 & 2 & & & $100(2)$ & $\begin{array}{l}\text { Slow activity, Spike, Spike- } \\
\text { wave, fast activity, HFO }\end{array}$ & & $100(2)$ & & \\
\hline
\end{tabular}




\section{References}

Agari T, Mihara T, Baba K, Kobayashi K, Usui N, Terada K, et al. Successful treatment of epilepsy by resection of periventricular nodular heterotopia. Acta Med. Okayama 2012; 66: 487492.

Aghakhani Y, Kinay D, Gotman J, Soualmi L, Andermann F, Olivier A, et al. The role of periventricular nodular heterotopia in epileptogenesis. Brain 2005; 128: 641-651.

Aubert S, Wendling F, Regis J, McGonigal A, Figarella-Branger D, Peragut JC, et al. Local and remote epileptogenicity in focal cortical dysplasias and neurodevelopmental tumours. Brain 2009; 132: 3072-3086.

Bagshaw AP, Jacobs J, Levan P, Dubeau F, Gotman J. Effect of sleep stage on interictal high-frequency oscillations recorded from depth macroelectrodes in patients with focal epilepsy. Epilepsia 2009; 50: 617-628.

Barkovich AJ, Guerrini R, Kuzniecky RI, Jackson GD, Dobyns WB. A developmental and genetic classification for malformations of cortical development: Update 2012. Brain 2012; 135 : $1348-1369$.

Bartolomei F, Barbeau E, Gavaret M, Guye M, McGonigal A, Regis J, et al. Cortical stimulation study of the role of rhinal cortex in deja vu and reminiscence of memories. Neurology 2004; 63: 858-864.

Bartolomei F, Chauvel P, Wendling F. Epileptogenicity of brain structures in human temporal lobe epilepsy: A quantified study from intracerebral EEG. Brain 2008; 131: 1818-1830.

Bartolomei F, Cosandier-Rimele D, McGonigal A, Aubert S, Régis J, Gavaret M, et al. From mesial temporal lobe to temporoperisylvian seizures: A quantified study of temporal lobe seizure networks. Epilepsia 2010; 51: 2147-2158. 
Battaglia G, Chiapparini L, Franceschetti S, Freri E, Tassi L, Bassanini S, et al.

Periventricular nodular heterotopia: Classification, epileptic history, and genesis of epileptic discharges. Epilepsia 2006; 47: 86-97.

Catenoix H, Mauguière F, Guénot M, Ryvlin P, Bissery A, Sindou M, et al. SEEG-guided thermocoagulations: A palliative treatment of nonoperable partial epilepsies. Neurology 2008; 71 : $1719-1726$.

Catenoix H, Mauguière F, Montavont A, Ryvlin P, Guénot M, Isnard J. Seizures Outcome After Stereoelectroencephalography-Guided Thermocoagulations in Malformations of Cortical Development Poorly Accessible to Surgical Resection. Neurosurgery 2015; 77: 9-14.

Chevassus-Au-Louis N, Congar P, Represa A, Ben-Ari Y, Gaïarsa JL, Gaiarsa J-L. Neuronal migration disorders: heterotopic neocortical neurons in CA1 provide a bridge between the hippocampus and the neocortex. Proc. Natl. Acad. Sci. U. S. A. 1998; 95: 10263-8.

Christodoulou JA, Walker LM, Del Tufo SN, Katzir T, Gabrieli JDEE, Whitfield-gabrieli $\mathrm{S}$, et al. Abnormal structural and functional brain connectivity in gray matter heterotopia. Epilepsia 2012; 53: 1024-1032.

Colombet B, Woodman M, Badier JM, Bénar CG. AnyWave: A cross-platform and modular software for visualizing and processing electrophysiological signals. J. Neurosci. Methods 2015; 242: 118-126.

Cossu M, Fuschillo D, Cardinale F, Castana L, Francione S, Nobili L, et al. Stereo-EEGguided radio-frequency thermocoagulations of epileptogenic grey-matter nodular heterotopy. J. Neurol. Neurosurg. Psychiatry 2014; 85: 611-617.

Cossu M, Fuschillo D, Casaceli G, Pelliccia V, Castana L, Mai R, et al. Stereoelectroencephalography-guided radiofrequency thermocoagulation in the epileptogenic zone: a retrospective study on 89 cases. J. Neurosurg. 2015; 123: 1358-67. 
Dubeau F, Tampieri D, Lee N, Andermann E, Carpenter S, Leblanc R, et al.

Periventricular and subcortical nodular heterotopia A study of 33 patients. Brain 1995; 118: $1273-1287$.

Farquharson S, Tournier J-D, Calamante F, Mandelstam S, Burgess R, Schneider ME, et al. Periventricular Nodular Heterotopia: Detection of Abnormal Microanatomic Fiber Structures with Whole-Brain Diffusion MR Imaging Tractography. Radiology 2016; 281: 896-906.

Ferrari-Marinho T, Perucca P, Mok K, Olivier A, Hall J, Dubeau F, et al. Pathologic substrates of focal epilepsy influence the generation of high-frequency oscillations. Epilepsia 2015; 56: 592-598.

Guenot M, Isnard J, Ryvlin P, Fischer C, Ostrowsky K, Mauguiere F, et al. Neurophysiological monitoring for epilepsy surgery: The Talairach SEEG method - Indications, results, complications and therapeutic applications in a series of 100 consecutive cases. Stereotact. Funct. Neurosurg. 2002; 77: 29-32.

Jacobs J, Levan P, Chtillon CD, Olivier A, Dubeau F, Gotman J. High frequency oscillations in intracranial EEGs mark epileptogenicity rather than lesion type. Brain 2009; 132: $1022-1037$.

Kobayashi E, Bagshaw AP, Grova C, Gotman J, Dubeau F. Grey matter heterotopia: What EEG-fMRI can tell us about epileptogenicity of neuronal migration disorders. Brain 2006; 129: 366-374.

Kothare S V, VanLandingham K, Armon C, Luther JS, Friedman A, Radtke RA. Seizure onset from periventricular nodular heterotopias: depth-electrode study. Neurology 1998; 51: $1723-7$.

Lagarde S, Bonini F, McGonigal A, Chauvel P, Gavaret M, Scavarda D, et al. Seizureonset patterns in focal cortical dysplasia and neurodevelopmental tumors: Relationship with 
surgical prognosis and neuropathologic subtypes. Epilepsia 2016; 57: 1426-1435.

Li LM, Dubeau F, Andermann F, Fish DR, Watson C, Cascino GD, et al. Periventricular nodular heterotopia and intractable temporal lobe epilepsy: Poor outcome after temporal lobe resection. Ann. Neurol. 1997; 41: 662-668.

Palmini A, Gambardella A, Andermann F, Dubeau F, da Costa JC, Olivier A, et al. Intrinsic epileptogenicity of human dysplastic cortex as suggested by corticography and surgical results. Ann. Neurol. 1995; 37: 476-487.

Petit LF, Jalabert M, Buhler E, Malvache A, Peret A, Chauvin Y, et al. Normotopic cortex is the major contributor to epilepsy in experimental double cortex. Ann. Neurol. 2014; 76: 428442.

Roehri N, Lina J, Mosher JC, Bartolomei F, Benar CG. Time-frequency strategies for increasing high frequency oscillation detectability in intracerebral EEG. 2016; 2: 1-12.

Roehri N, Pizzo F, Bartolomei F, Wendling F, Bénar CG. What are the assets and weaknesses of HFO detectors? A benchmark framework based on realistic simulations. PLoS One $2017 ; 12$

Scherer C, Schuele S, Minotti L, Chabardes S, Hoffmann D, Kahane P. Intrinsic epileptogenicity of an isolated periventricular nodular heterotopia. Neurology 2005; 65: 495-496.

Shafi MM, Vernet M, Klooster D, Chu CJ, Boric K, Barnard ME, et al. Physiological consequences of abnormal connectivity in a developmental epilepsy. Ann. Neurol. 2015; 77: 487503.

Talairach J, Tournoux P, Musolino A, Missir O. Stereotaxic exploration in frontal epilepsy. Adv. Neurol. Front. Lobe Seizures Epilepsies 1992; 57: 651-688.

Tassi L, Colombo N, Cossu M, Mai R, Francione S, Lo Russo G, et al. Electroclinical, MRI and neuropathological study of 10 patients with nodular heterotopia, with surgical outcomes. 
Brain 2005; 128: 321-337.

Tassi L, Pasquier B, Minotti L, Garbelli R, Kahane P, Benabid AL, et al. Cortical dysplasia: Electroclinical, imaging, and neuropathologic study of 13 patients. Epilepsia 2001; 42: $1112-1123$.

Thompson SA, Kalamangalam GP, Tandon N. Intracranial evaluation and laser ablation for epilepsy with periventricular nodular heterotopia. Seizure 2016; 41: 211-216.

Tschuluun N, Wenzel JH, Katleba K, Schwartzkroin PA. Initiation and spread of epileptiform discharges in the methylazoxymethanol acetate rat model of cortical dysplasia: Functional and structural connectivity between CA1 heterotopia and hippocampus/neocortex. Neuroscience 2005; 133: 327-342.

Tyvaert L, Hawco C, Kobayashi E, LeVan P, Dubeau F, Gotman J. Different structures involved during ictal and interictal epileptic activity in malformations of cortical development: An EEG-fMRI study. Brain 2008; 131: 2042-2060.

Valton L, Guye M, McGonigal A, Marquis P, Wendling F, Régis J, et al. Functional interactions in brain networks underlying epileptic seizures in bilateral diffuse periventricular heterotopia. Clin. Neurophysiol. 2008; 119: 212-223.

Watrin FF, Manent JB, Cardoso C, Represa A. Causes and consequences of gray matter heterotopia. CNS Neurosci. Ther. 2015; 21: 112-122.

Zhang LL, Collier PA, Ashwell KWS. Mechanisms in the induction of neuronal heterotopiae following prenatal cytotoxic brain damage. Neurotoxicol. Teratol. 1995; 17: 297311. 